\title{
What does the literature say about resilience in refugee people? Implications for practice
}

\section{Mary Hutchinson}

Griffith University

Victoria University

\section{Pat Dorsett}

Griffith University

\begin{abstract}
Refugee people experience many trials prior to arriving in Australia and face ongoing challenges associated with re-settlement. Despite facing such difficulties many refugee people demonstrate enormous strength and resilience that facilitates their re-settlement process. The authors' experience however suggests that professionals working with refugee people tend to focus on the trauma story to the neglect of their strengths. At times this means resilience is overshadowed by a dominant Western deficits model that defines refugee people as traumatised victims. Pathologising the trauma story of refugee people may further alienate refugee people from full inclusion into Australian life by denying their inherent resilience in the face of extraordinary life experiences. This article reviews Australian and International literature to explore factors that contribute to refugee resilience such as personal qualities, support and religion. The review also identifies elements that may impede resilience including; language barriers, racism, discrimination, and labelling the trauma story. The literature suggests refugee resilience moves beyond the Western individualised notion of resilience to a more communal construction of resilience that includes refugee people's broader social context. The literature highlights important practice implications and the authors respond to the findings by reflecting on their own practice
\end{abstract}


experience and considering implications for a more inclusive anti-oppressive strengthsbased approach to work with refugee people.

Keywords: refugee, resilience, strengths, trauma

\section{Introduction}

This paper arose from the critical practice reflections of the first author and her concerns with the emphasis on the trauma experience of refugee people settling in Australia with little acknowledgement of the resilience and coping strengths demonstrated. These concerns lead to an investigation of the literature and consideration of alternative approaches to working with refugee people. In this paper we will firstly present her reflections as a context to the literature review which follows and will conclude with a consideration of the implications for social work practice with refugee people settling in Australia. These discussions have a significant implication for the inclusion of refugee people into mainstream Australian communities. It is suggested that the focus on trauma and trauma counselling at the expense of resilience and coping strengths may in fact contribute to or prolong the alienation of refugee people and impede their inclusion into Australian communities. The reflections of the first author provided the impetus for this work and are presented below in the first person to maintain the reflective and interactive nature of this work.

When I first started working in the refugee service sector as a social worker some years ago, I could not help but notice that there was a great deal of attention given to the trauma/torture aspects of the refugee experience with very little attention given to refugee people's strengths and capabilities. As a practitioner seeking to adopt a strengths-based, inclusive approach to my practice, this presented challenges as the service environment was predominately guided by a western psychopathology/deficits model. In Australia, there is an array of refugee services: refugee health services, settlement services, settlement case coordination, complex case support, refugee minor program, migrant resource centres and specialist trauma counselling available to support refugee people's needs. In this complex service environment refugee people's resilience seemed to be overlooked by the professional's view of what is helpful or unhelpful and what was needed for 
successful settlement. Moreover, professional expertise appeared to undermine refugee people's capacity for self-determination, growth potential, and sense of agency.

In my experience when refugee people arrive in a new country, they often feel overwhelmed at the prospect of resettlement, excited at the expectations of living in a new country, and anxious and disturbed by the realities of cultural change. Additionally, they may display an ambiguity about their new home and immediate surroundings. Such reactions [cross cultural strain] are deemed to be normal and natural responses early in a person's resettlement process (Zapf, 1991; Sue \& Sue, 2012). However, I observed that many "new arrivals" [refugee people and families] were routinely referred for specialist trauma counselling services. These routine referrals seemed to be based on an assumption of trauma. Furthermore, many clients had little understanding of the counselling/services and frequently felt obliged to agree to referrals so as to continue to receive other essential services or be part of the service system. Thus the assumption of traumatisation was embedded in the service delivery systems supporting refugee resettlement in Australia. Refugee people entering a new country and adapting to a new lifestyle need time to settle into their new surroundings and to be given an opportunity to find their way and draw upon existing resources and strengths. In my work with refugee people I see explicit expressions of strength and resourcefulness almost every day. My experience in the field suggests that the resilience in refugee people settling in Australia is often overlooked and not utilised in practice settings.

The term refugee is used to define a person who has been forced to leave and live outside their country of nationality due to fear, threat, violence or persecution and war (United Nations High Commissioner for Refugees [UNHCR], 2011). In the year 2010-2011, the Australian Government granted 13,799 refugee/humanitarian visas (permanent residency), to people from various places around the world (Department of Immigration \& Citizenship [DIAC], 2011). It is estimated that currently there are approximately 9.7 million refugees displaced worldwide (Australian Human Rights Commission [AHRC], 2011).

Although many people from war-torn countries experience and witness traumatic events, the majority of those who survive do not develop significant mental disorders (Rosner, Powell \& Butollo, 2003). Refugee people show enormous 
"courage and strength by coping with conditions of extreme deprivation and surviving against adversity" (Tiong, 2006, p. 8). Once refugee status is established, a person has to deal with the demands of resettlement in a foreign country and loss and separation from their family and culture (Schweitzer, Melville, Steel \& Lacherez, 2006). Despite this turmoil, research suggests many refugee people go on to thrive in their new country and surroundings (El-Bushra \& Fish, 2004). Professionals, however, continue to utilise a western medical model that places refugee experiences of hardship, deprivation and distress in the terrain of psychopathology, rather than seeing it as a 'normal' response to an abnormal situation (American Psychological Association, 2009). As a result, refugee resilience is often obscured by the pervasiveness of the trauma narrative in refugee people's lives (Papadopoulos, 2001). While definitions of resilience differ, it is often associated with a person's ability to bounce back "following adversity and challenge and connotes inner strength, competence, optimism, flexibility and the ability to cope effectively when faced with adversity" (Wagnild \& Collins, 2009, p. 1). As a result of the reflections described above, an extensive literature review was undertaken to investigate factors that build resilience in refugee people and to explore elements that may impede resilience. The literature review and practice implications are presented in the following sections.

\section{Methodology}

An extensive literature search was conducted in 2011 and updated in September 2012. The search included the Griffith University library catalogue and electronic databases: ProQuest Research, Expanded Academic ASAP, Taylor \& Francis, Oxford, Sage Journals, PsycINFO, Wiley online library and Informit. Initially the search was restricted to Australian sources using the terms refugee and resilience, refugee and wellbeing, refugee and hope, refugee and settlement and refugee and health. The Australian search results predominantly focused on the Sudanese refugee community (Schweitzer, Greenslade \& Kagee, 2007; Schweitzer, Melville, Steel \& Lacherez, 2006; Shakespeare-Finch \& Wickham, 2009; Marlowe, 2009; Khawaja, White, Schweitzer \& Greenslade, 2008). Due to the limitations of the Australian literature (less than 30) the search was expanded to include other international sources using Boolean logic methods to expand on terms that may 
resemble resilience including: refugee and coping, refugee and strengths and refugee and resources. A Google Internet search revealed further literature.

Abstracts were reviewed and sources that had a focus on aspects of refugee resilience were included. Any literature that offered new meanings and understandings about refugee resilience was included in this review. Refugee service provider websites were also searched for relevant data but publications primarily focused on the psychopathology aspects of refugee trauma, acculturation and resettlement and were excluded from the review. Research conducted in relation to refugee resilience factors include a number of international qualitative studies with refugee men and women, families, youth, minors and information from professionals working with the refugee community.

\section{Findings}

The literature review identified a number of factors that either build or impede resilience in refugee people.

\section{Factors that build resilience}

\section{Personal qualities}

Internal resources were identified in the literature as a major contribution to refugee resilience. Toth's (2003) study with refugee women suggests that personal qualities such as optimism, adaptability and perseverance helped them to cope and survive. A belief in one's own inner strength to deal with life's challenges, (Brough, Gorman, Ramirez \& Westoby, 2003) a positive attitude, and having hope for a good future helped refugee women to cope (Khawaja, White, Schweitzer \& Greenslade, 2008). The determination to cope was seen as a component of taking control, rather than being a victim (Gorman, Brough \& Ramirez, 2003). Shakespeare-Finch and Wickham's (2009) study suggests that looking ahead to the future strengthens refugee people's resilience. One participant in the study stated: "I am going to lay a good foundation for me, for my children, for my family" (Shakespeare-Finch \& Wickham, 2009, p. 38). Similarly, a study with the 'Lost Boys of Sudan' identified that an acceptance of the situation and refocusing on the present and the future helped some of the boys to cope (Luster, Qin, Bates, Johnson \& Rana, 2009). Pulvirenti and Mason's (2011) study revealed the construction of resilience with refugee women was linked to the idea of 'moving on' from adversity rather than the 
concept of 'bouncing back' from it.

\section{Support}

Apart from personal qualities being linked to refugee resilience, external forms of support were also prominent in the construction of resilience. A number of qualitative studies emphasised the importance of family (including extended family), friends, and community in bolstering refugee resilience in the resettlement process. Support included both the reciprocal processes of giving and receiving support. In a qualitative study, Bosnian refugee women cited the support received from their spouses, children and family as a key factor in building their resilience. As one participant stated: "once you have family you cannot give up, you have to stay strong for them" (Sossou, Craig, Ogren \& Schnak, 2008, p. 378). Likewise, qualitative studies conducted in Australia with the refugee community also confirmed support and its relationship to resilience (Schweitzer, Greenslade \& Kagee, 2007). Apart from receiving support from friends and family, refugee people also utilised their own ethnic community to help them cope and adjust to their new way of life (Schweitzer et al., 2007). Mixing and having a strong attachment with their ethnic peers, assisted young refugee people to cope with resettlement, and was associated with significantly "greater levels of well-being in the psychological, social and environmental domains" (Correa-Velez, Gifford \& Barnett, 2010, p. 1404).

Lenette, Brough and Cox's (2012) qualitative research with single refugee women found resilience building is connected to 'person-environment interactions', rather than being linked to static, individual-inner traits. Moreover, the women's narratives suggest resilience is underpinned by a dynamic process which is fluid, contextual and constructed continually throughout ordinary, day-to-day processes involving challenges and opportunities. Pulvirenti and Mason's (2011) study with service providers working with refugee women experiencing violence, also confirm that resilience is a process rather than a fixed inner personal characteristic. Moreover, the service providers argue such essentialist individualised notions of resilience can be used by governments to reduce their social responsibility in providing services and resources, and this can lead to blaming an individual for their current circumstances (Pulvirenti \& Mason, 2011). Furthermore, the service providers suggest that the women's resilience is constructed in an environment of external support, not just from friends, and within their own ethnic communities but 
their resilience is conditional upon the assistance of the wider host community (Pulvirenti \& Mason, 2011). These studies suggest resilience moves beyond the essentialist notion of resilience that resides within an individual alone, an inner trait, to encompass personal qualities that also interact within a social context. This equates to the concept of social construction that argues that knowledge and understanding about the world comes from exchanges between people in their social, cultural and historical context (Payne, 2005). Thus, human meanings made from such interactions "are never singular, individual or simply subjective, never outside the social, but have shared intersubjective meaning within the cultural nexus of power and knowledge" (Brown \& Augusta-Scott, 2007, p. 9).

\section{Religiosity and spirituality}

Religion and spirituality are strongly identified as another major factor contributing to refugee people's resilience. Several studies have shown that religion in its various forms is linked to enhancing a person's psychological and physical wellbeing (Green \& Elliot, 2010). For example a study with 62 young orphaned participants suggested that Buddhist spirituality promoted resilience in children in many ways: it offered them "structure, encouraged cognitive restructuring, acceptance of the trauma, cultivated a sense of control and the rituals promoted integration in the broader community" (Fernando \& Ferrari, 2011, p. 70). Schweitzer et al. (2007) suggests a belief in God helped people regain control and meaning in their lives. Another study found some refugee people resigned themselves to the situation, and believed fate was out of their hands and in God's hands (Khawaja et al., 2008). Spirituality gave other refugee people strength: whether it was a belief in a "higher power, calling on dead relatives or something deep inside," spirituality assisted refugee people to cope through hard times (Sossou et al., 2008, p. 378).

\section{Obstacles to resilience}

A number of factors which challenged resilience in refugee people were also identified in the literature. These included: language barriers, racism and discrimination and labelling or trauma stories.

\section{Language barriers}

The studies reviewed identified problems associated with language barriers as a significant obstacle to building resilience. Shakespeare-Finch and Wickham (2009) 
argue that people were not able to express themselves and communicate which left them feeling powerless and disadvantaged. Language difficulties also affected refugee people's job prospects and housing and full inclusion in Australian life (Schweitzer et al., 2007). Reedy (2007) reported that young refugee people learn the language much sooner than their parents. As a result, the traditional child and parent relationship is reversed, whereby the young person becomes the cultural broker and communicator for their family. This increase in responsibility places a lot of pressure and strain on young refugee people and the parent and child relationship (Reedy, 2007).

\section{Racism and discrimination}

Research suggests that racism and discrimination also hinders refugee people's resilience. According to Brough et al. (2003), young refugees experienced racism, especially within the school environment and this potentially affected their capacity to develop relationships with Australians. The Correa-Velez et al. (2010) study with 97 young refugee participants concurs with the above findings, but goes further to argue that one out of five participants had been bullied by other students or discriminated against because of their ethnicity, race or religion. Other research also reported incidents of physical violence, verbal abuse and denying access to services (Shakespeare-Finch \& Wickham, 2009, p. 37). Racism can hinder a refugee and migrant's settlement process, their growth and functionality, leading to distress, isolation and a lack of belonging (Brotherhood of St Lawrence, 2012).

A VicHealth Survey (2008) into ethnic racism and discrimination asserted that people born in countries from non-English speaking backgrounds are "four times as likely to experience discrimination in policing and housing, three times as likely to experience discrimination in the workplace and twice as likely to experience discrimination in the education system" (p. 5). Additionally people born in countries from non-English speaking backgrounds are twice as likely to experience discrimination at a sporting/public event, a restaurant or a shop (VicHealth, 2008, p. 5). Racism and discrimination can adversely affect an individual's physical health and psychological wellbeing, often involving the unfair treatment of an individual or group that results in unequal opportunities (VicHealth, 2008). 


\section{Labelling - the trauma story}

The traditional western mental health model tends to focus on psychopathological elements of refugee experiences and "assigns western diagnostic labels such as post-traumatic stress disorder (PTSD) and other anxiety disorders to natural responses and visceral coping strategies to dire situations" (Raymond, 2005, p. 28). There is no argument that it is important to have knowledge about the psychological aspects of trauma; however a western model may deny the resilience of survivors: terms such as "scarred for life and vulnerable become the descriptors of the body and embed the refugee master status" (Marlowe, 2009, p. 186). One participant (as cited in Marlowe, 2009, p. 189) stated:

We need to get rid of that thinking that our people are traumatised. We were traumatised, yes this is true and that is fine. But that does not mean what we are. We are something different and we can provide. We can offer. We can contribute.

Papadopoulos and Hildebrand (1997, p. 209) argue that it is quite common for professionals to conceptualise refugee people within a deficit or pathology framework and that the refugee trauma discourse is so prevalent that it permeates our whole social fabric. The politicians, the media and the general public have been so "saturated by the trauma discourse that all assume that, more or less, all refugees are traumatised" (Papadopoulos, 2001, p. 409). The impact of this ubiquitous trauma story - the concept that "war renders whole populations traumatized and dysfunctional, problematizes" and disqualifies refugee peoples' capacity for self-governance (Pupavac, 2002, p. 490). Assigning a PTSD classification to the refugee experience categorises refugee people and diverts attention away from their own views and understandings of distress and their choice of treatment (Summerfield, 1999). For instance, Tsoulis (2008) tells the story of a refugee client who had been a client at a migrant resource centre. The client always had a positive disposition and good sense of humour and had recently been hospitalised in a psychiatric ward in public hospital. Prior to the client's admission to the hospital he was working in a cold room in a meat factory lifting heavy boxes of meat. Some months later he left the job unable to cope with his work anymore. The client expressed symptoms of back and shoulder aches, headaches and a cold 
stomach; he never experienced symptoms like this before (Tsoulis, 2008). He became very depressed due to his symptoms and he thought there was 'something wrong with his brain', for feeling like this but he was told [by the health and employment workers] it was because he was a refugee [rather than his work conditions] and in need of ongoing trauma counselling (Tsoulis, 2008, p. 1). Unfortunately, the workers directly connected the client's current situation to a traumatised refugee background.

Papadopoulos (2001) asserts: therapists tend to link refugee people's current difficulties to their refugee background overlooking refugee people's positive attributes and resilience. Moreover, Papadopoulos (2001) argues that the focus on the trauma story changes the power dynamic in the working relationship, where the clients can end up relying completely on the therapist for help in a way that fosters cycles of dependence. If a refugee person is "essentially pathologised and seen as exclusively a victim, invariably the therapist is likely to occupy the saviour role" (Papadopoulos, 2005, p. 37). Watters (2001) suggests despite the variability in research findings of PTSD in refugee populations, sociologists pointed to the construction and use of statistics to equate high levels of PTSD in refugee people "in arguing for resources to develop particular programs and to mobilise resources in the mental health arena" (p. 1710). In addition, the author argues that the biomedical taxonomy is not just a "scientific label but a mechanism whereby resources, be they professional help or financial support can be directed in accordance to established norms of clinical need" (Watters, 2001, p. 1710). Moreover, Watters (2001) asserts that welfare organisations wanting to help refugee people may have to diagnose (i.e. assign a label to) the person's issue in a clinical context to establish eligibility for services. This perpetuates and posits refugee people within a deficit framework and exposes the inequalities in the service system.

Refugee clients are often pressured to engage in services they know little about, to meet funding demands placed on agencies or to access essential settlement services (Tsoulis, 2008). When refugee people are asked what they think would help, most are likely to identify economic and social factors rather than psychological assistance (Summerfield, 1999). The trauma discourse overrides the fundamental needs of refugee people (Ryan, Dooley \& Benson, 2008). While some refugee people may need and appreciate psychological/therapeutic intervention it seems likely that such a dialogical relationship may not succeed until the person's 
fundamental needs are first addressed. Maslow's (1998) psychological humanism asserts: that humans are motivated by multiple needs and that needs are hierarchical by nature. Located at the base level: 'physiological needs: (to satisfy hunger \& thirst), safety needs: (to feel safe and secure), belonging and love needs: (to belong and be accepted, love and be loved), esteem needs (self-esteem, achievement, independence and competence) and at the higher level is selfactualisation: (living up to one's fullest potential)' (Griggs, 2009, p. 271). Maslow asserts lower level needs have to be satisfied before higher level needs can be considered (Romero \& Kemp, 2007). However, Yang (2003, p. 214) points out, that the way the self, achieves self- actualisation varies across cultures, suggesting that within collective cultures self-actualisation is linked to the sense of a collective consciousness and the reciprocal responsibilities of community members to each other, community and country. Western individualist cultures centre on three core rudiments: "independence, uniqueness and the self as a unit of analysis" (Snyder, Lopez \& Pedrotti, 2011, p. 466).

Focusing on the refugee trauma story and past sufferings neglects refugee people's present concerns and fails to examine the impact of forced migration and settlement/adjustment issues. As Gemignani (2011) argues:

The past is linked to persecution and psychological stress; the present and the future are a result of such a past and, therefore are seen under the magnifying glass of what has previously occurred. Whether directly (e.g., PTSD patients) or indirectly (e.g., in the definition of a refugee), the overarching discourse assumes a deterministic relationship between the refugee's psychological state and traumatic past. In other words, from the traumatic experience on, the life of the person is seen as indissolubly bound to trauma (p. 140).

\section{Discussion}

The literature identifies both internal and external factors that build resilience and highlights negative influences that obstruct resilience in refugee people. The findings suggest refugee people utilise many pathways to construct resilience and this adds further meaning and understanding to an often thin description of resilience that 
pertains to individual, inner traits alone. Importantly, the review provides a broader understanding of refugee resilience that can inform and contribute to practice outcomes that assist refugee people in their settlement and inclusion to Australian life. The results suggest alternative practice approaches for those working with refugee/diverse communities. The review was limited by the paucity of literature available on refugee resilience. However, the literature review brings together a mix of International studies as well as Australian research in relation to refugee resilience. In the following discussion, the authors highlight key practice implications for practitioners entering or working in this field and provide practice reflections in response to the findings.

\section{Key implications for practice - practice reflections}

\section{Anti-oppressive: strengths based approaches}

The literature emphasises the problem of labelling refugee people and how the trauma discourse can pathologise, oppress and diminish refugee people's resilience. It is therefore crucial for practitioners wanting to assist refugee people in building resilience that they are not part of a process that impedes refugee resilience. If practitioners continue to focus on the trauma aspects of a refugee people's lives, then the factors for building resilience in refugee people will most likely be denied. One way to ensure our practice focuses on the construction of refugee resilience is by utilising strengths-based practice approaches.

Strengths-based frameworks can assist practitioners to identify refugee people's strengths and resources and assist them in mobilising pathways to build resilience. Many commentators argue that working from a strengths-based perspective is paramount in counteracting the expert mental health professions traditional stronghold on illness, dysfunction and problem definition (Chazan, Kaplan \& Terio, 2000). A Strengths-based philosophical/approach stands in opposition to a deficits approach, in that it does not focus on person's so called shortcomings, deficits or dysfunction, nor does it label or disempower a person (McCashen, 2007). A strengths perspective draws on a "power with" [clients] approach rather than a "power over" [clients] approach-viewing clients as the experts of their own lives and situations (McCashen, 2007; Saleebey, 2006; Corcoran, 2012). Moreover, when people become the experts about others issues and "try and fix them, those who are 
facing the problem are denied the opportunity to participate, take control and learn" (McCashen, 2007, p. 10). At the core of strengths perspective is the belief that individuals, families and communities have strengths and capabilities to grow and transform (McCashen, 2004).

The trauma story, the labelling, the negative stereotyping of refugee people, can impact heavily on a person's sense of self and ultimately their resilience. My experience in the field of working with young refugee men suggests that they are very proud of their cultural heritage and of what they have achieved since arriving in Australia. While hoping for a better future, many of the men express concern that the "refugee" label and its negative connotations holds them back in life, restricting them to a life as a refugee rather than being included as equal members in society. As a result, refugee people can experience internalised oppression. Internalised oppression concerns "the incorporation and acceptance, by individuals within an oppressed group, of the prejudices against them within a dominant society" (Australian Psychological Society, 1997, p. 22). The personal effects of internalised oppression present itself at times in my work with refugee men and women. Clients make negative statements in the context of being a refugee: they blame themselves, isolate themselves and withdraw from other people in their ethnic community. Antioppressive practice can assist clients to self-define their identity through a process of conscientization (Mullaly, 2010). Conscientization involves a dialogue between the practitioner and the client that is focused on "perceiving and exposing social and political, economic contradictions and injustices" (Barkat, Podder, Halim, Osman, Badiuzzaman \& Hoque, 2007, p. 1). It concerns the client gaining a new level of awareness, learning about oppression to take action against the oppressive elements in their life.

There is no dispute that some refugee people do experience ongoing mental health distress from trauma, and that they also benefit greatly from the support they receive from specialist trauma counselling services. However, the authors caution practitioners to be alert to the persuasiveness of the trauma discourse and its associated pathology, and how it impacts heavily on the way workers view and work with refugee people. The trauma story influences the assessment and intervention process and ultimately a practitioner's capacity to assist clients in bolstering resilience. At a practice level, taking a respectful position of "not-knowing" ensures that workers do not engage in oppressive practices with clients that may deny or 
obscure resilience. The not-knowing position requires a stance, an expression, in which the practitioners communicate a genuine curiosity about the client's story with "a need to know more about what is being said, rather than conveying preconceived opinions and expectations about the client, the problem and what must be changed" (Anderson \& Goolishian, 1992, p. 29). To 'not know' requires that our understandings are not restricted by preceding experiences or theoretical formed truths, and knowledge (Anderson \& Goolishian, 1992). Moreover, a not-knowing stance, concerns honouring the client's truth, their narrative, and their unique lived experiences.

Through discussion with colleagues in the field, most refugee people prefer to talk about the present and the future. If refugee people do wish to talk and share some of their past experiences, most of the time it is said within the context of strength: their strength that they have gained from their past that has helped them to build resilience. Taking a solution-focused approach with refugee people is one way to reveal and re-discover a client's strength to solve problems. A solution-focused approach draws from a strength's perspective, and is helpful in the way that it separates the problem from the person, removing any blame or judgements, and viewing the problem as the problem, not the person as the problem (Milner \& O'Byrne, 2002). It creates and fosters a working environment that starts from where the client is "now" and where they would like to be and what it would take to get there (McCashen, 2007). Unlike other modalities, solution-focused therapy does not concentrate on the past or the historical roots of the problem, instead it is "attention orientated to a future without the problem, to build vision, hope and motivation for the client" (Corcoran, 2012, p. 8). Strengths-based practice approaches are empowering in the way that they can respond to assist clients in uncovering both internal and external factors that construct or contribute to resilience.

\section{Cultural competency, respect and sensitivity}

The findings also emphasise that resilience in refugee people is not essentially concerned with just one's innate qualities and strengths but extends further to encompass the person's external environment. This includes family, social support and ethnic community. When individuals from collective cultures are faced with adverse situations, they rely on their families and ethnic community for assistance, support and resources (Yip, 2008). People working with refugee communities who 
have an understanding of collective values will be motivated to adopt more inclusive practices that consider, the person's family, tribe-clan, significant others, ethnic community and leaders. These approaches represent a move beyond Western individualistic helping methods towards a more inclusive cultural competent and sensitive approach. Such inclusive practice interventions may include family/community/tribe members [at the client's request] being welcomed into the counselling room or practitioner's interview room [usually a sacrosanct space for one-to-one/face-to-face practice]. It is not uncommon in my work with the refugee communities, especially in the first few meetings, to have family or community members in the room with the client.

I remember when I first started working in the refugee sector; I was due to meet with a refugee client who wanted to see the social worker. I went out into the reception area and quietly called the person's name and I asked if they would like to accompany me into one of the rooms. The client stood up and to my surprise so did a few other people and everyone followed me into the room. The client informed me that their community members strongly shared her concern. It was a daunting and quite chaotic session but remains in my memory as a most compelling session. The level of sharing and learning was significant as we worked together to find a solution to the client's problems. This example portrays a dialogical relationship that can assist in building client resilience. It involves a shared enquiry, a "mutual process in which participants are in a fluid mode, characterised by people talking with each other as they seek understanding and generate meanings; it is an in-there-together, two way, give and take, back and forth exchange" (Anderson \& Goolishian, 1992; as cited in Anderson, 2011, p. 1 ). Gemignani (2011) asserts that "if psychological issues are collective (e.g., of a population or ethnic group), then responsibility to solve them will be shared with other persons and within the larger context of history, culture and society" (p. 150). Furthermore, arguing that this view challenges individualistic Western traditional medical and psychological models that place the responsibility of one's psychological issues solely at the level of the individual (Gemignani, 2011).

The literature identified that spirituality and religion is another important factor that helps build refugee people's resilience. In my experience, this is an accurate representation. In many refugee communities, religion and spirituality play a very important part, and for some refugee people their daily living activities are 
strongly governed by their faith and belief systems. At the direct practice level, a general awareness of spiritual matters is not sufficient to be effective in our work with clients. We "have to be able to deal with and be willing to engage in conversations" about spirituality and religiosity (Singer, 2006, p. 1). Spiritual competency [a component of cultural competency] involves the process of a practitioner being able to recognise and develop a cognizance of their own spiritual and religious values, beliefs and biases to consider what influence they may have on client assessment, engagement and interventions processes (Hodge \& Bushfield, 2006). Additionally, spiritual competence requires practitioners to have a non-judgmental attitude, an empathic understanding of the client's faith and beliefs, and an ability to co-develop appropriate interventions that are "relevant and sensitive to a client's spiritual worldview" (Hodge, 2004; as cited in Hodge \& Bushfield, 2006, p. 106). Practitioners' assessments also need to incorporate the client's spiritual and religious beliefs to increase our understanding of the role that faith plays, and its meaning in the lives of our clients and their ethnic community. Practitioners will then be further equipped to operationalise resilience factors, which encourage support and strength in the process of change.

Language barriers were also recognised in the literature as a hindrance to refugee people's resilience: not being able to speak the language and communicate excluded refugee people from full participation and access to Australian life. It is vital for refugee people to be able to communicate and express themselves in their own language and to connect with people in their host country. Being able to communicate is essential for refugee settlement, not only for a refugee person's future, but also for their optimal physical and mental health outcomes (Morris, Popper, Rodwell, Brodine \& Brouwer, 2009). Therefore, it is as imperative as it is ethical, that a refugee person's lived experience of the presenting problem/s are heard and correctly understood from their cultural frame of reference. This necessitates that practitioners use accredited/trained interpreters and genuinely work towards developing collaborative relationships with the interpreters "to ensure accurate and effective communication" (AASW, 2010; Miletic, Piu, Minas, Stankovska, Stolk \& Klimidis, 2006, p. 2). Moreover, qualified interpreters can help practitioners with the nuances involved in language and communication. For instance, communication is not directly interchangeable some word/s in the English language may have no corresponding word/s in another language (British 
Psychological Society, 2008). Furthermore, to have knowledge and a greater awareness of cultural paralinguistic cues when the client speaks, such as non-verbal elements of voice (complex series of sounds, voice modifications and silences) will enable practitioners to have less misinterpretation and a deeper understanding of their client (Raschotte, 1999, p. 3). Additionally, "to be alert for idiosyncratic, cultural and locale-specific meanings" (Murphy \& Dillon, 2010 p. 123) will foster an environment that helps to build refugee resilience.

Whenever possible practitioners should use the same interpreter to help build trust and rapport with the client and maintain continuity of care. It not appropriate to use family members to translate information except in dire situations where no other alternative is available. Moreover, young family members "lack the vocabulary and emotional maturity to serve as effective interpreters" (Sue \& Sue, 2012, p. 195). Children should not be put in a situation where they are privy to confidential psychological or medical information about their parents or older family members. It is unfair and places undue stress on the child (Sue \& Sue, 2012).

Racism and Discrimination is also cited in the literature as another barrier to refugee people's resilience. Practitioners sometimes think that discrimination and racism only happens "out there" in the community, at the broader level of society, not at the practice level. They are assuming that their position and training guarantees them immunity from any involvement in racist and discriminatory practices. Be assured, at the practice level, cultural values and belief systems can and do collide and this is where cultural competence is dynamically enacted to counteract such practices. Cultural competency and reflective practice requires us to challenge our own assumptions, ideals, values, biases and belief systems (Fitzgerald, 2000). It concerns gathering knowledge about different cultures and learning from our interactions with clients in order to gain skills to connect and engage more richly and sensitively in our practice (Stewart, 2006; ECCV, 2006; Chang-Muy \& Congress, 2009).

At the level of direct practice, cultural competency implies that practitioners do not privilege their ideals, values and belief systems over other people's worldviews. At times, this can be a difficult task, especially if working with clients from diverse cultures. In my practice, I work with a number of refugee families who come from countries where the social system is patriarchal. Therefore, any discussions or conversations I have concerning family/children will need to be directed to and 
conducted with the father-the head of the family; even though it is clear that the mother is the primary care giver of the children. Most times the mother is present with the children in the room; her husband will do most of the talking whilst his wife remains respectively quiet, consistent with her cultural role and expectations.

At times I find it hard to sit with such cultural difference and I find myself reflecting on my Western ideals, values and beliefs. I reflect on what it means to be a woman in my family, and in broader society. I also reflect from a feminist perspective that strongly upholds gender equality and women having a voice. Importantly, I reflect on how cultural differences impact on my practice with my clients and how they influence my interaction. I recall a time when my values and beliefs impacted on the discussion with a client regarding a family issue. The father, the head of the family, had made a decision regarding one of children. I remember asking his wife, the mother, what she felt about the decision that had been made. She gave me such an intense look of disbelief [as if I should have known better than to have not asked her that question, or put her in such a position]. Through the interpreter she explained that her husband is the one that makes such decisions. I quickly withdrew any further focus of probing her view and learnt a valuable lesson that day. What may at first appear to be inclusive practices from a Western point of view, may be construed by refugee clients to be seen as disrespectful, exclusionary and discriminatory practice that could prevent clients from seeking assistance or accessing services in the future. Furthermore, practitioners need to be alert to the dominant and powerful role their culture plays in "making some worldviews valid, while making others invalid" (Hick, Fook \& Pozzuto, 2005, p. 92). In practice, our attention needs to be focused on our communication with clients leaving our own values and belief systems "at the door and respecting differences" (Meares, 2007, p. 88). Cultural sensitivity involves an acknowledgment of cultural differences, having respect and valuing differences.

\section{Anti-discriminatory practice}

Racism and discrimination directed towards refugee people in Australia is often subtle and covert. One example encountered frequently in my practice is discriminatory practices towards refugee people in the private rental market. Rental agents and landlords often perceive refugee people stereotypically as less desirable tenants. At times agents will refuse to accept rental applications or advise that the 
property has already been rented (even when the property is still on the market and available for rent). Having limited income, no English language, no rental history and no employment history can leave refugee clients even more vulnerable to such racist and discriminatory practices. This is further exacerbated by structural problems such as shortage of government/public housing for people on limited incomes. The tensions created by these discriminatory practices and structural issues can intensify the sense of exclusion and erode resilience in refugee people. Advocacy is one way social workers and human service practitioners can assist refugee people to address the inequitable discrimination, racism and structural barriers that they may experience as they settle into Australian communities. However, advocacy should always be enacted within a broader framework of practice that fosters client/community empowerment (Ife, 1999). Practitioners should provide clients and their ethnic communities with translated information about rights (such as tenancy obligations and rights) to enhance awareness of the system, their rights, and to facilitate the development of self-advocacy skills. Moreover, empowering, "antidiscriminatory practice removes barriers to equal treatment or better access to services" (Payne, 2011, p. 87) and contributes to refugee resilience.

\section{Summary and Conclusion}

The major themes identified as contributing to refugee resilience are both internal and external: personal qualities, support, religion and spirituality. Refugee people reach out to family, friends, peers and their own ethnic community. There were also key barriers noted in this review that may also interfere with refugee people's resilience. These included language, racism, discrimination and labelling-the trauma story. Further research is needed regarding refugee resilience with a focus on refugee people's strengths and abilities, external supports and incorporating inclusive practices that include anti-oppressive strengths-based approaches that reinforce refugee resilience, rather than emphasise pathology and the refugee trauma. 


\section{References}

American Psychological Association. (2009). Working with refugee children and their families: An update for mental health professionals. Retrieved April 15, 2011, from http://www.apa.org/pubs/info/reports/refugees-health-professionals.pdf

Anderson, H. (2011). Post modern social constructionist therapies. Retrieved October 10, 2011, from http://www.harleneanderson.org/writings/postmoderntherapieschapter.htm

Anderson, H., \& Goolishian, H. (1992). The client is the expert: A not-knowing approach to therapy. In S. McNamee \& K. Gergen (Eds.), Therapy as social construction (pp. 25-35). Newbury Park, CA: SAGE.

Australian Association of Social Workers. (2011). Code of ethics 2010. Retrieved September 30, 2011, from http://www.aasw.asn.au/document/item/740

Australian Human Rights Commission: AHRC (2011). Asylum seekers and refugees. Retrieved April 30, 2011, from http://www.hreoc.gov.au/racial discrimination/face facts 05/refugee.html

Australian Psychological Society. (1997). Racism and prejudice: Psychological perspectives. Retrieved October 10, 2011, from http://www.psychology.org.au/Assets/Files/racism position paper.pdf

Barkat, A., Poddar, A., Halim, S., Osman, A., Badiuzzaman, M. D., \& Hoque, S. (2007). Development as conscientization. Retrieved October 10, 2011, from http://www.hdrcbd.com/pcs pdf/19\%20NGO/01.\%20DEVELOPMENT\%20A S\%20CONSCIENTIZATION\%20The\%20Case\%20of\%20Nijera\%20Kori\%20i n\%20Bangladesh.pdf

British Psychological Society. (2008). Working with interpreters in health settings: Guidelines for psychologists. Retrieved October 10, 2011, from http://www.ucl.ac.uk/clinicalpsychology/traininghandbook/sectionfiles/Appen dix 6 B PS guidance on working with interpreters.pdf

Brotherhood of St Laurence. (2012). Tackling racism at the broader community level. Retrieved September 2, 2011, from http://www.bsl.org.au/media/scripts/setup-analytics.aspx?did=10385

Brough, M., Gorman, D., Ramirez, E., \& Westoby, P. (2003). Young refugees talk about well-being: A qualitative analysis of refugee youth mental health from three states. Australian Journal of Social Issues, 38(2), 193-208.

Brown, C., \& Augusta-Scott, T. (Eds.). (2007). Narrative therapy: Making meaning, making lives. London: SAGE.

Chang-Muy, F., \& Congress, E. (Eds.). (2009). Social work with immigrants and refugees: Legal issues, clinical skills and advocacy. New York: Springer.

Chazin, R., Kaplan, S., \& Terio, S. (2000). The strengths perspective in brief treatment with culturally diverse clients. Crisis Intervention and TimeLimited Treatment, 6(1), 41-50.

Corcoran, J. (2011). Helping skills for social work direct practice. New York: Oxford University Press.

Correa-Velez, I., Gifford, S., \& Barnett, A. (2010). Longing to belong: Social inclusion and well-being among youth with refugee backgrounds in the first three years in Melbourne, Australia. Social Science \& Medicine, 17(8), 1399-1408. doi:10.1016/j.socscimed.2010.07.018

Department of Immigration and Citizenship. (2011). Australian refugee and humanitarian program. Retrieved September 20, 2012, from http://www.immi.gov.au/media/fact-sheets/60refugee.htm\#d 
El-Bushra, J., \& Fish, K. (2004). Protecting vulnerable groups: Refugees and internally displaced persons. Retrieved September 30, 2011, from http://www.huntalternatives.org/download/44 section5.pdf

Ethnic Communities Council of Victoria: ECCV. (2006). Cultural competence guidelines and protocols. Retrieved September 17, 2011, from http://eccv.org.au/library/doc/CulturalCompetenceGuidelinesandProtocols.pd f

Fernando, C., \& Ferrari, M. (2011). Spirituality and resilience in children of war in Sri Lanka. Journal of Spirituality and Mental Health, 13(1), 52-77. doi: 10.1080/19349637.2011.547138

Fitzgerald, M. H. (2000). Establishing cultural competency for mental health professionals. In V. Skultans \& J. Cox. (Eds.), Anthropological approaches to psychological medicine: Crossing bridges (pp. 184-200). London: Jessica Kingsley.

Gemignani, M. (2011). The past if past: The use of memories and self-healing narratives in refugees from the former Yugoslavia. Journal of Refugee Studies, 24(1), 132-156. doi: 10.1093/jrs/feq050.

Gorman, D., Brough, M., \& Ramirez, E. (2003). How young people from culturally diverse backgrounds experience mental health: Some insights for mental health nurses. International Journal of Mental Health Nursing, 12(3), 194202. doi: 101140527.

Green, M., \& Elliot, M. (2010). Religion health and psychological well-being. Journal of Religion and Health, 49(2), 149-163. doi: 10.1007/s10943-009-9242

Griggs, R. (2009). Psychology: A concise introduction (2 ${ }^{\text {nd }}$ ed.). New York: Worth.

Hick, S., Fook, J., \& Pozzuto, R. (Eds.). (2005). Social work a critical turn. Toronto: Thompson Educational.

Hodge, D., \& Bushfield, S. (2006). Developing spiritual competence in practice. Journal of Ethnic \& Cultural Diversity in Social Work, 15(3-4), 101-127. doi: 10.1300/J051v15n03_05

Ife, J. (1999). Rethinking social work: Towards a critical practice. Australia: Longman.

Khawaja, N., White, K., Schweitzer, R., \& Greenslade, J. (2008). Difficulties and coping strategies of Sudanese refugees: A qualitative approach. Transcultural Psychiatry, 45(3), 489-512. doi:10.1177/1363461508094678

Lenette, C., Brough, M., \& Cox, L. (2012). Everyday resilience: Narratives of single refugee women with children. Qualitative Social Work, 11(5), 1-17. doi: 10.1177/1473325012449684

Luster, T., Qin, D., Bates, L., Johnson, D., \& Rana, M. (2009). The lost boys of Sudan: Coping with ambiguous loss and separation from parents. American Journal of Orthopsychiatry, 79(2), 203-211. doi: 10.1037/a0015559

Marlowe, J. (2009). Beyond the discourse of trauma: Shifting the focus on Sudanese refugees. Journal of Refugee Studies, 23(2), 183-198. doi: 10.1093/jrs/feq013

Maslow, A. (1998). Toward a psychology of being ( $3^{\text {rd }}$ ed.). New York: John Wiley \& Sons. 
McCashen, W. (2004). Communities of hope: A strength-based resource for building community. Bendigo: St Lukes Innovative Resources.

McCashen, W. (2007). The strengths approach: A strengths based resource for sharing power and creating change. Bendigo: St Lukes Innovative Resources.

Meares, P. A. (2007). Cultural competence: An ethical requirement. Journal of Ethnic \& Cultural Diversity in Social Work, 16(3-4), 83-92. doi: 10.1300/J051v16n03_06

Miletic,T., Piu, M., Minas, H., Stankovska, M., Stolk,Y., \& Klimidis, S. (2006). Victorian transcultural psychiatric unit: Guidelines for working effectively with interpreters in mental health settings. Retrieved October 1, 2011, from http://www.vtpu.org.au/docs/interpreter/VTPU GuidelinesBooklet.pdf

Milner, J., \& O’Bryne, P. (2002). Brief counselling: Narratives and solutions. Basingstoke: Palgrave.

Morris, M., Popper, S., Rodwell, T., Brodine, S., \& Brouwer, K. (2009). Healthcare barriers of refugees post resettlement. Journal of Community Health, 34(6), 529-538. doi: 10.1007/s10900-009-9175-3

Mullaly, R. (2010). Challenging oppression and confronting privilege ( $2^{\text {nd }}$ ed.). Canada: University Press.

Murphy, B., \& Dillon, C. (Eds.). (2010). Interviewing in action in a multicultural world. $\left(4^{\text {th }}\right.$ ed.). United States: Brooks/Cole.

Papadopoulos, R. K. (2001). Refugee families: Issues of systemic supervision. Journal of family Therapy, 23(4), 405-422.

Papadopoulos, R. K. (Ed.). (2005). Therapeutic care for refugees: No place like home. London: Karnac.

Papadopoulos, R. K., \& Hidlebrand, J. (1997). 'Is home where the heart is? 'Narratives of oppositional discourses in refugee families. In R. K. Papadopoulos \& J. Byng-Hall (Eds.), Multiple voices: Narrative in systemic family psychotherapy (pp. 206- 236). London: Duckworth.

Payne, M. (2011). Humanistic social work: Core principles in practice. Chicago: Lyceum Books.

Pulvirenti, M., \& Mason, G. (2011). Resilience and survival: Refugee women and violence. Current Issues in Criminal Justice. 23(1), 37-52.

Pupavac, V. (2002). Pathologizing populations and colonizing minds: International psychosocial programs in Kosovo. Alternatives, 27(4), 489-511.

Raschotte, L. (1999). Affective cross cultural communication based on paralinguistic clues. (Honours Thesis, Florida State University, United States of America). Retrieved September 20, 2011, from http://digitool.fcla.edu/R/HI1R7X6N3NLAI4QBPPIL47FQQ5TV8QPB9Y6LKP 1Y8LAHK9S7UR-01755?func=dbin-jumpfull\&object $\mathrm{id}=158306 \&$ local base $=\mathrm{GEN} 01$ \&pds handle $=$ GUEST

Raymond, R. (2005, November). The mental health impacts of trauma on young refugee people and therapeutic interventions promoting resilience. Hopes fulfilled or dreams shattered? From resettlement to settlement (pp. 1-61). Proceedings of a Conference held at the University of New South Wales, Sydney. $\quad$ Retrieved April 10, 2011, from www.crr.unsw.edu.au/media/File/Refugee Resilience.pdf 
Reedy, J. (2007). The mental health conditions of Cambodian refugee children and adolescence. (Honours Thesis: Ohio State University, United States of America). Retrieved April 30, 2011, from https://kb.osu.edu/dspace/bitstream/handle/1811/25191/CAMBODIAN REF UGEE CHILDREN THESISJR.pdf;jsessionid=FF2064FC1F200F7A643F52 8EC732B359? sequence $=1$

Romero, A., \& Kemp, S. (2007). Psychology demystified. New York: McGraw-Hill.

Rosner, R., Powell, S. \& Butollo, W. (2003). Post traumatic stress disorder: Three years after the siege in Sarajevo. Journal of Clinical Psychology, 59(1), 4155. doi: 10.1002/jclp.10116

Ryan, D., Dooley, B., \& Benson, C. (2008). Theoretical perspectives on postmigration adaptation and psychological well-being among refugees: Towards a resource-based model. Journal of Refugee Studies, 21(1), 1-18.

Saleeby, D. (2006). The strengths perspective in social work practice. $\left(5^{\text {th }}\right.$ ed.). Australia: Pearson Education.

Schweitzer, R., Melville, F., Steel, Z., \& Lacherez, P. (2006). Trauma, post-migration living difficulties, and social support as predictors of psychological adjustment in resettled Sudanese refugees. Australian and New Zealand Journal of Psychiatry, 40(2), 179-187. doi: 10.1111/j.14401614.2006.01766.x

Schweitzer, R., Greenslade, J., \& Kagee, A. (2007). Coping and resilience in refugees from the Sudan: A narrative account. Australian and New Zealand Journal of Psychiatry, 41(3), 282-288. doi:1080/00048670601172780

Shakespeare-Finch, J., \& Wickham, K. (2009). Adaption of Sudanese refugees in an Australian context: Investigating helps and hindrances. International Migration, 48(1), 23-46. doi: 10.1111/j.1468-2435.2009.00561.x

Singer, J., (Presenter) \& Boyd, N. (Interviewee). (2006, May 26). Incorporating religion and spirituality into social work practice with African Americans [Social Work Podcast Audio Program]. Retrieved October 10, 2011, from http://socialworkpodcast.blogspot.com/2010/05/incorporating-religion-andspirituality.html

Snyder, C.R., Lopez, S., \& Pedrotti, J. (2011). Positive psychology: The scientific and practical explorations of human strengths $\left(2^{\text {nd }}\right.$ ed.). Los Angeles: SAGE.

Sossou, M., Craig, C., Ogren, H., \& Schnak, M. (2008). A qualitative study of resilience factors of Bosnian refugee women resettled in the southern United States. Journal of Ethnic \& Cultural Diversity in Social Work, 17(4), 365-385.

Stewart, S. (2006). Cultural competence in health care. Retrieved September 17, 2011, from http://dhi.gov.au/

Sue D., \& Sue, D. (2012). Counselling the culturally diverse: Theory and practice. $\left(6^{\text {th }}\right.$ ed. $)$. New Jersey: John Wiley \& Son's.

Summerfield, D. (1999). A critique of seven assumptions behind psychological trauma programmes in war-affected areas. Social Science \& Medicine, 48(10), 1449-1462.

Tiong, A. (2006). Health needs of newly arrived African refugees from a primary health care perspective. Retrieved, April 10, 2011, from www.health.vic.gov.au/healthstatus/downloads/dhsreport20060922.pdf

Toth, J. (2003) Resilience: The experience of immigrant and refugee women. (Master Thesis, University of Manitoba, Manitoba Heritage Thesis Database). Retrieved April 12, 2011, from http://mspace.lib.umanitoba.ca/handle/1993/3801 
Tsoulis, E. (2008). Successful inclusion must respond to diverse needs. Australian Mosaic, 18, 41-42.

United Nations High Commissioner for Refugees: UNHCR. (2009). Facts and resources. Retrieved April 12, 2011, from http://www.unhcr.org/pages/49c3646c4d6.html

VicHealth (2008). Ethnic and race-based discrimination as a determinant of mental health and wellbeing. Retrieved, September 15, 2011, from http://www.vichealth.vic.gov.au/ /media/ProgramsandProjects/MentalHealth andWellBeing/Publications/Attachments/ResearchSummary Discrimination. $\underline{\text { ash }}$

Wagnild, G., \& Collins, J. (2009). Assessing resilience. Journal of Psychosocial Nursing, 47(12), 28-33. doi:10.3928/02793695-20091103-01

Watters, C. (2001). Emerging paradigms in the mental health care of refugees. Social Science\& Medicine, 52(11), 1709-1718.

Yang, K. S. (2003). Beyond Maslow's culture-bound linear theory: A preliminary statement of the double-y model of basic human needs. In V, MurphyBerman \& J. J. Berman (Eds.). Nebraska Symposium on Motivation: Cross cultural differences in the perspectives of self. (pp. 175-255). Lincoln: University of Nebraska Press.

Yip, K. S. (Ed.). (2008). Strengths based perspective in working with clients with mental illness: A Chinese cultural articulation. New York: Nova Science.

Zapf, M. (1991). Cross-cultural transitions and wellness: Dealing with culture shock. Retrieved October 21, 2011, from http://www.krcmar.informatik.tumuenchen.de/...nsf/.../Paper\%2021.pdf

\section{Biographical Notes}

Mary Hutchinson is a qualified Social Worker who currently works on a refugee health program in the Community Health sector in Melbourne. She has worked in this position for over four years. Prior to this Mary has had experience working in both the public and private health sector. Mary also works for Victoria University in Melbourne as a liaison social worker, supporting social work students on their field education placements. Mary recently completed a Masters Degree in Mental Health Practice at Griffith University's School of Human Services and Social Work.

Dr Pat Dorsett is a Senior Lecturer at Griffith University, School of Human Services and Social Work, Brisbane Australia. She has extensive social work practice and research experience in a variety of health and rehabilitation fields. Her current research interests are focused on adjustment and coping issues. Pat has been instrumental in the development and evaluation of innovative community-based programs especially for groups who are vulnerable or marginalised. Her work with people with disabilities has been published in peer reviewed journals and featured at national and international conferences. 